\title{
AORTIC SINUS ANEURYSMS
}

\author{
BY \\ N. M. GIBBS AND E. L. HARRIS \\ From the Royal Surrey County Hospital, Guildford \\ Received May 23, 1960
}

Aneurysm of the aortic sinuses (sinuses of Valsalva) is a rare condition. The three accepted causes are congenital malformations, bacterial infections, and syphilis. Two other rare causes have been described, namely cystic medial necrosis of Erdheim and acute rheumatic aortitis (Jones and Langley, 1949).

We are concerned only with congenital aneurysms in this paper. Thirty-six acceptable cases have been reported previously of which 26 ruptured to form cardio-aortic fistulæ. Maude Abbott (1936) was able to find only 12 examples in her collection of 1000 cases of congenital heart disease. Jones and Langley (1949) recorded 25 cases of congenital aneurysms of the aortic sinus. Oram and East (1955) reviewed 23 cases of aortic sinus aneurysms, including two of their own that ruptured into the right side of the heart. Feldman et al. (1956) and Lee et al. (1956) described two further cases.

Our object is to describe two new cases which have certain features of interest, and to discuss the embryological development.

\section{CASE REPORTS}

Case 1. An ex-Royal Marine, aged 36, was discharged from the services as fit in 1946 . He worked as a tool maker and enjoyed very good health until three weeks before admission to hospital, when while walking to work he suddenly became short of breath and felt nauseated. At no time did he have any pain. He continued to work, but his dyspnœea became increasingly worse and on July 22, 1958 he was admitted to hospital. There was no history of rheumatic fever or of recurrent sore throats.

On examination he was dyspnœic at rest with slight cyanosis and a malar flush. The pulse was 120 a minute, regular in rhythm and collapsing in character, and equal on each side. Pistol shot sounds were audible over femoral arteries; capillary pulsation was present. The blood pressure was 120/20 mm. Hg. The jugular venous pressure was raised just above the sternal angle. The apex beat was in the 5th intercostal space just outside the mid-clavicular line and a right parasternal heave with a systolic thrill was felt in the 3rd intercostal space. The pulmonary second sound was greatly accentuated. A harsh loud systolic murmur was audible along the left sternal border, radiating to the apex. A loud early diastolic murmur and a short mid-diastolic rumbling were heard at the apex. Crepitant râles were heard over both lungs and were maximal at the bases. The liver was enlarged two fingers' breadth below the right costal margin and was tender and pulsating. There was no peripheral œdema. The electrocardiogram showed right axis deviation with some rotation of the heart. The chest radiograph showed pulmonary congestion with a straight left cardiac border. The urine contained a trace of albumin. The Wassermann reaction and Kahn test were negative. Blood culture was negative. The hæmoglobin was $13.0 \mathrm{~g}$. per $100 \mathrm{ml}$., the white blood cells 15,000 per cu. $\mathrm{mm}$. with a normal differential count. A diagnosis of ruptured aneurysm of an aortic sinus was made and he was treated with mercloran, digoxin, oxygen, and aminophylline. His condition gradually deteriorated with increasing dyspnœa, jaundice, and a falling pulse pressure, and he died seven days after admission. 
Necropsy. The body was that of a big muscular man.

The heart (485 grams, Fig. 1 and 2) showed conspicuous left ventricular dilatation with numerous petechial hæmorrhages on the visceral endocardium. An aneurysmal sac $(3 \times 2 \mathrm{~cm}$. $)$ with an apical rupture $(1 \mathrm{~cm}$. in length) protruded from the membranous portion of the interventricular septum between the cusps of the tricuspid valve. The wall of the sac was thin and semitranslucent and originated from the right (coronary) sinus which was deficient at the base. The aortic valve cusps and remaining sinuses were normal.

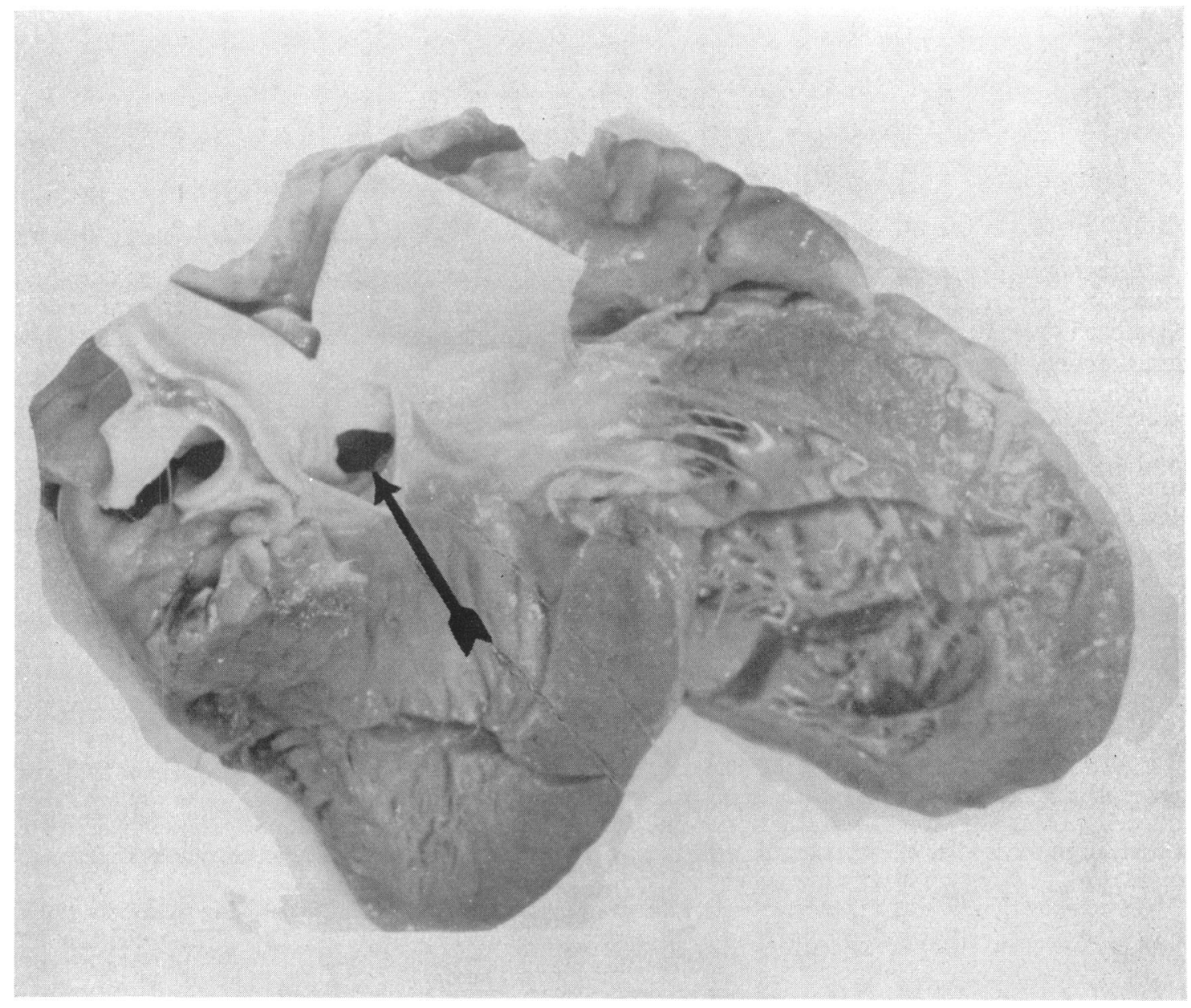

Fig. 1.-Case 1. Orifice of aneurysm in right anterior (coronary) sinus.

The mitral valve was normal. The myocardium was pale in colour and showed a typical subendocardial "thrush breast" appearance due to fatty change. There was moderate left and right ventricular hypertrophy (left ventricle $1.6 \mathrm{~cm}$.; right ventricle $0.6 \mathrm{~cm}$.) The coronary arteries showed occasional patches of atheroma but there was no evidence of calcification. The pulmonary artery and aorta were healthy.

Histological examination of the heart and aorta showed no evidence of acute rheumatism, syphilis, cystic medial necrosis, or bacterial endocarditis.

Necropsy Diagnosis. Rupture of a congenital aneurysm of the right coronary sinus of Valsalva into the right ventricle. Congestive cardiac failure.

Case 2. A woman, aged 24, complained of dyspnœa on exertion for a year since June, 1949 which had 


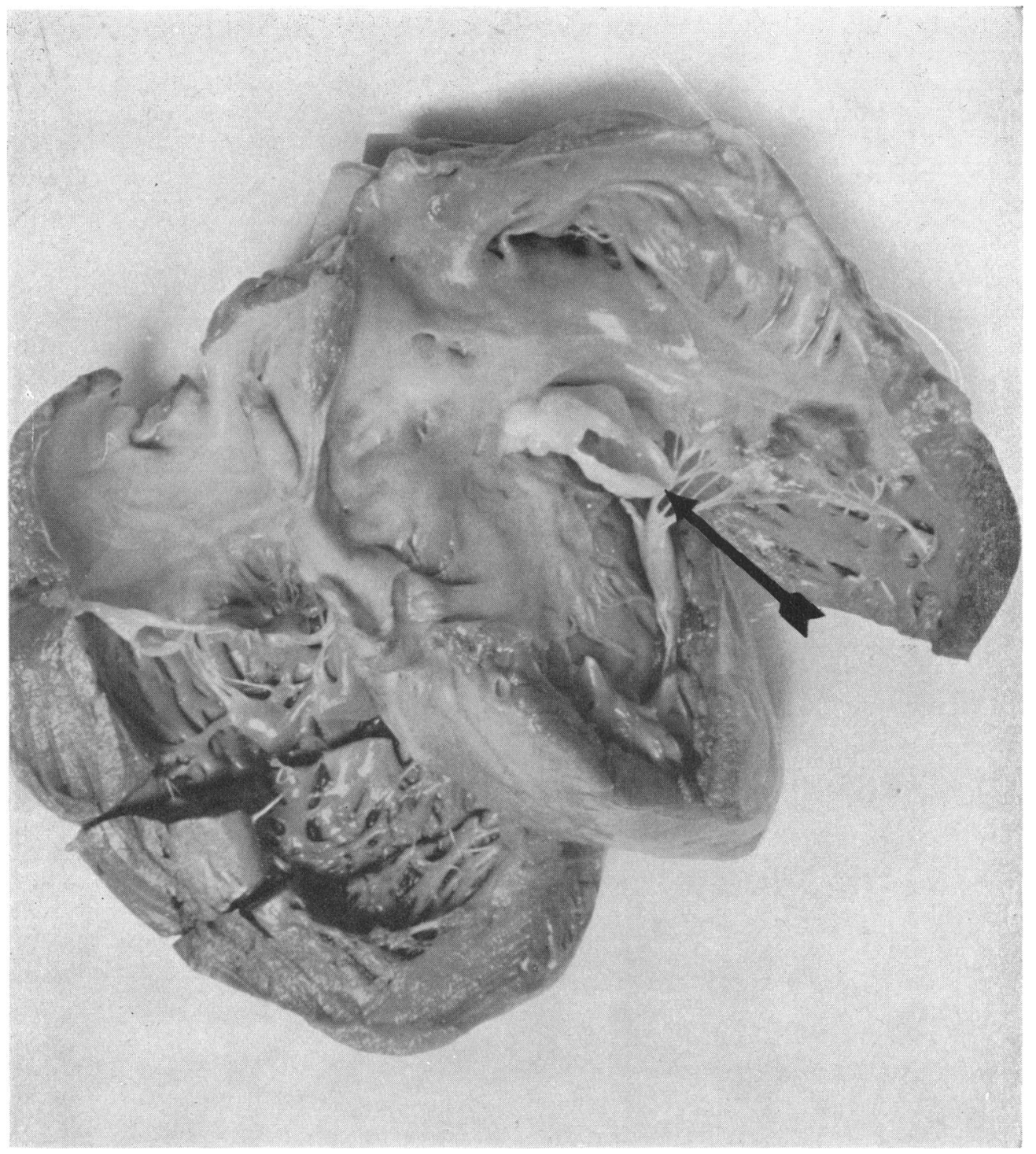

FIG. 2.-Case 1. Ruptured aneurysm protruding between the cusps of the tricuspid valve.

become more severe in the last three months with the occurrence of attacks of nocturnal breathlessness. Three weeks before admission she was confined to bed with frequent vomiting and she had a hæmoptysis. She complained of loss of weight, night sweats, and a persistent cough. Her general condition deteriorated and she was admitted to the Bristol Royal Infirmary in May, 1950.

There was no history of rheumatic fever or chorea. A doubtful cardiac murmur had been heard on routine clinical examination as a child and she had attended regular follow-up cardiac clinics. No abnormal physical signs were detected until a year before when an aortic diastolic murmur was heard as well as a doubtful mitral diastolic murmur. The electrocardiogram showed left axis deviation in March 1949 and left bundle-branch block four months later.

On examination, she was orthopnœic with a malar flush but she was otherwise pale. There was dependent œdema of the lower limbs. The pulse was 98 a minute, collapsing, with regular rhythm. Pistol shot 
sounds were audible over the femoral arteries and capillary pulsation was present. The blood pressure was $150 / 40 \mathrm{~mm}$. $\mathrm{Hg}$. The jugular venous pressure was raised. The apex beat was palpable in the 6th intercostal space at the anterior axillary line. An aortic diastolic murmur was present and the pulmonary second sound was accentuated. Crepitant rales were heard throughout both lung fields. There was a small right pleural effusion. The liver was enlarged three fingers' breadth below the right costal margin.

A clinical diagnosis of cardiac failure due to rheumatic aortic regurgitation was made.

Two days after admission to hospital, she became cyanosed and a drop of systolic blood pressure occurred. She responded temporarily to oxygen but died the same day.

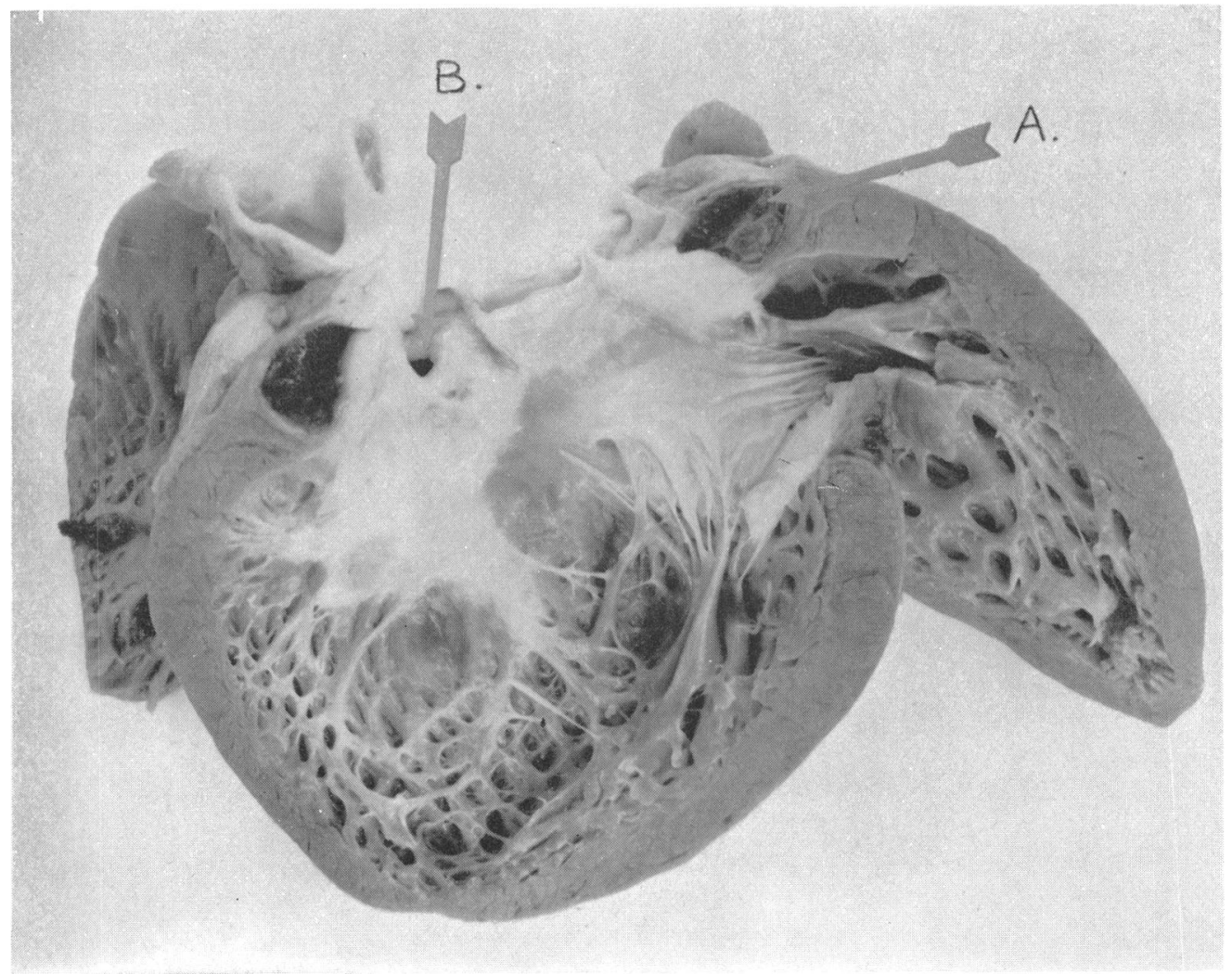

Fig. 3.-Case 2. (A) Left ventricle, showing bisected left anterior (coronary) sinus aneurysm. (B) Absent right anterior aortic valve cusp, and the orifice of the right anterior (coronary) sinus aneurysm.

Necropsy. The body was that of a well developed woman $40.9 \mathrm{~kg}$. in weight and 1.5 metres in length. The heart (436 grams) was dilated and hypertrophied and there was dilatation of the left and right atria. The mitral and tricuspid valves were normal. The right ventricle $(1.5 \mathrm{~cm}$. in thickness) was dilated and hypertrophied. The pulmonary valve was normal. The aortic valve $(6 \mathrm{~cm}$. in circumference) showed the following abnormalities. There was an aneurysm of the left anterior (coronary) sinus, $4 \mathrm{~cm}$. in breadth and extending $2 \mathrm{~cm}$. inferiorly into the left ventricular muscle wall (Fig. 3). This contained some organizing thrombus. The posterior (non-coronary valve) cusp was thickened but otherwise normal. The right anterior (coronary) aortic valve cusp was absent. There was an orifice with rounded fibrous edges $(0.7 \times 0.5 \mathrm{~cm}$.) lying in the base of the sinus, extending into a cavity $(6.5 \times 3 \mathrm{~cm}$.) lying in the interventricular septum (Fig. 3, 4, 5). This aneurysm extended from the membranous ventricular septum posteriorly to within $1 \mathrm{~cm}$. of the anterior descending branch of the left coronary lying in the anterior wall of the interventricular septum. Inferiorly, the aneurysm extended $2.5 \mathrm{~cm}$. below the tricuspid valve ring. 


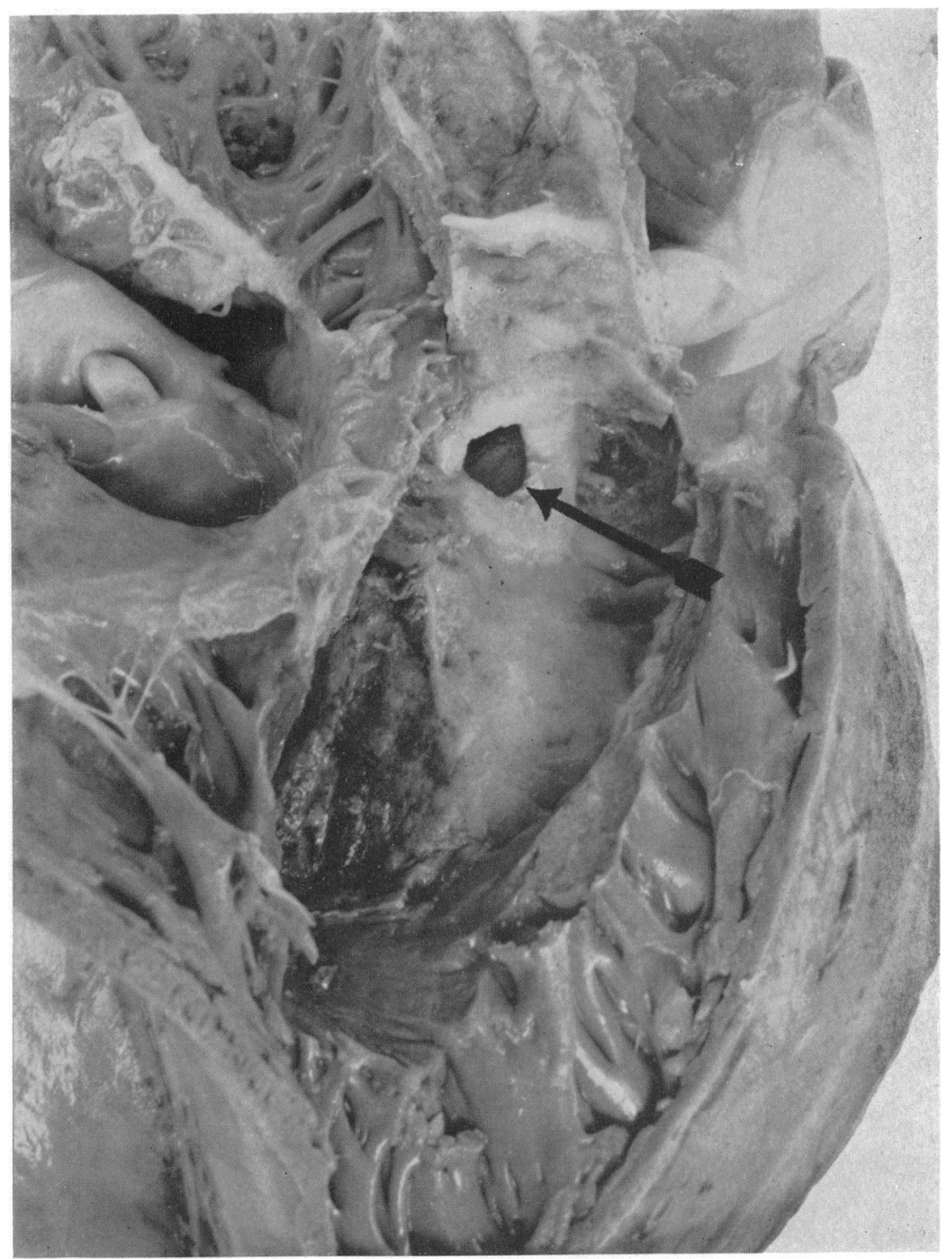

FIG. 4.-Case 2. The right ventricular wall of the interventricular septum has been reflected to show the aneurysmal cavity. The orifice of the aneurysm in the right anterior (coronary) sinus is shown.

The walls of the upper part of the aneurysm cavity were fibrous and this portion of the aneurysm measured $3 \times 3 \mathrm{~cm}$. The walls of the lower part of the cavity were formed of muscle of the interventricular septum and appear to have been produced by a recent rupture of the aneurysm with further downward extension. The muscle lining the left ventricle adjacent to the interventricular septum and inferior to the right anterior (coronary) aortic sinus showed subendocardial fibrosis and formed the left wall of the upper part of the aneurysm. At the lower extremity of the aneurysm the walls (formed by the muscle of the interventricular septum) were $1 \mathrm{~mm}$. only in thickness and there was some endocardial hœmorrhage at this site. There was slight atheroma of the aortic valve. The ascending and descending aorta were normal but there was considerable atheroma of the abdominal aorta. The coronary arteries were not involved by the aneurysms of the two anterior sinuses of Valsalva and were patent. The renal arteries were normal. 
Histological examination of the heart and aorta showed no evidence of acute rheumatism, syphilis, cystic medial necrosis, or bacterial endocarditis.

Necropsy Diagnosis. Congenital absence of right anterior aortic valve cusp. Congenital aneurysms of right and left (coronary) sinuses of Valsalva. Rupture of right (coronary) sinus aneurysm into the interventricular septum. Congestive heart failure.

\section{EMBRYOLOGY}

In the past there has been confusion about the naming of the aortic sinuses but Walmsley's (1929) nomenclature is used here as recommended by recent authors. The precursors of the valves at the distal end of the bulbus cordis consist of four endocardial cushions. The completion of the distal bulbar septum which separates the aortic and pulmonary orifices results in the division of

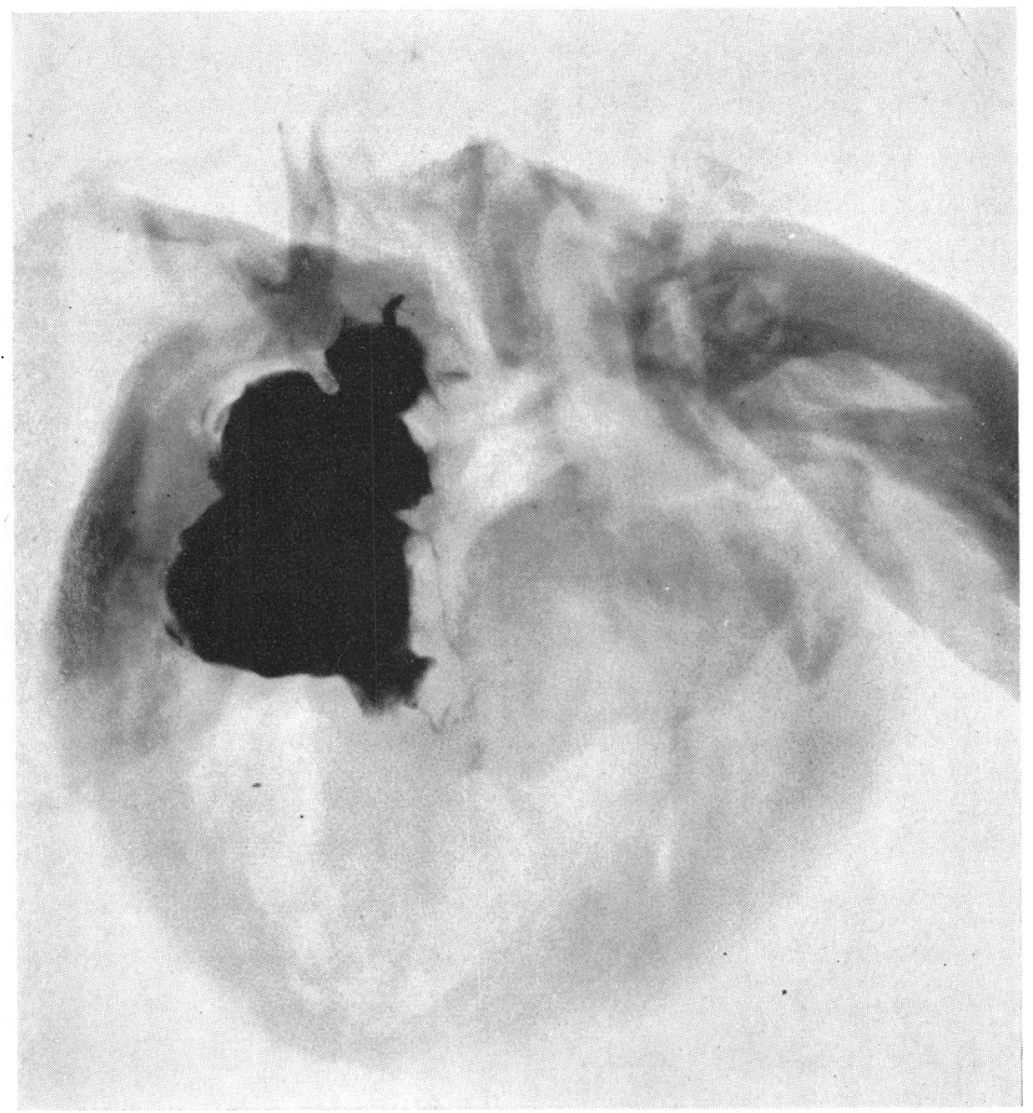

Fig. 5.-Case 2. The aneurysm of the right anterior (coronary) sinus has been filled with barium at necropsy. The radiograph shows the aneurysm lying in the interventricular septum.

each lateral cushion into two parts. The number of thickenings is increased by this means to six of which three are associated with the pulmonary orifice and three with the aortic orifice. These thickenings form the rudiments of the aortic and pulmonary valves (Fig. 6) while the pouches between the valves and the walls of the vessels gradually enlarge and form the sinuses of the aorta.

The aortic sinus aneurysms collected by Abbott (1919) arose from the right coronary sinus and 

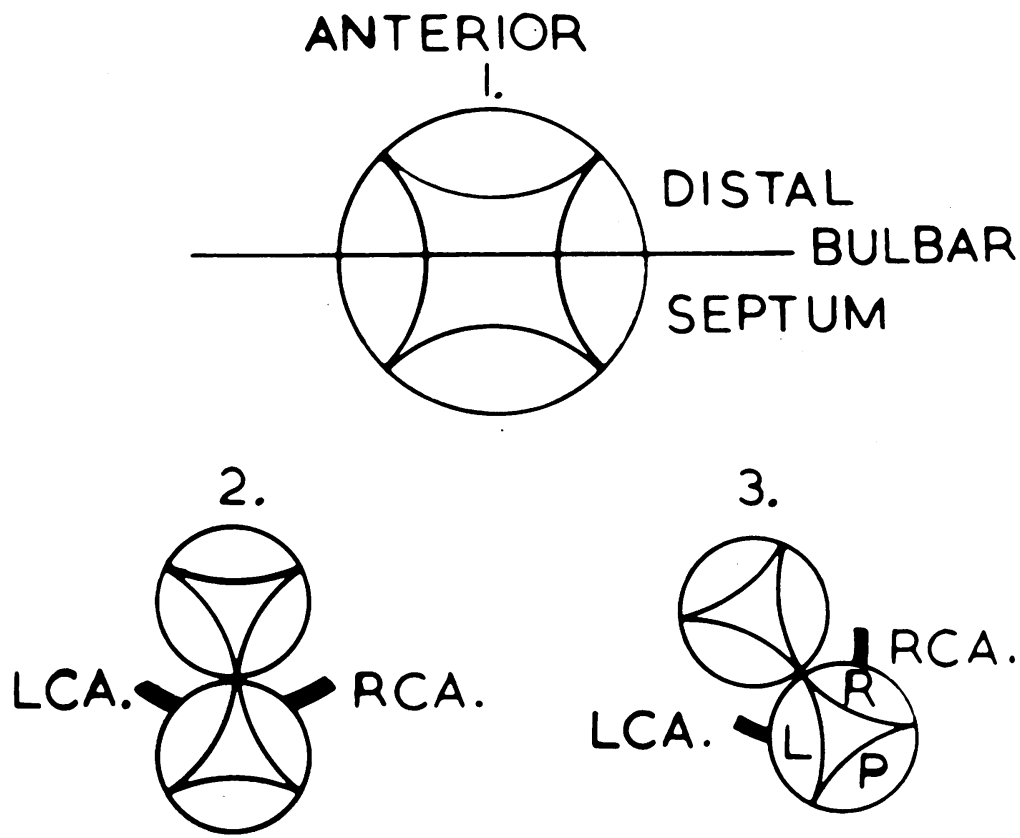

\section{POSTERIOR}

Fig. 6.-The embryological development of the pulmonary an aortic valves from the bulbus cordis. L. $=$ Left anterior (coronary) sinus. R.=Right anterior (coronary) sinus. P.=Posterior (non-coronary) sinus. L.C.A. $=$ Left coronary artery. R.C.A. $=$ Right coronary artery.

she postulated a developmental defect in the distal bulbar septum. The distal bulbar septum can be related only to two of the three aortic sinuses, namely the left and right coronary sinuses. This is a contradiction of the conclusion reached by Jones and Langley (1949) who claimed that all congenital aneurysms have been confined to the right coronary sinus and the non-coronary sinus, and that up to 1949, no aneurysm arising from the left coronary sinus had been reported: they have not included Higgins' (1934) case where there is little doubt that the aneurysm arose from the left coronary sinus. Case 2 demonstrates that a congenital aneurysm can rise from the left coronary sinus. A defect in the development of the distal bulbar septum cannot explain the occurrence of aneurysms of the posterior (non-coronary) sinus (Herson and Symons, 1946; Venning, 1951; and Lee et al., 1956) or of all three aortic sinuses (Micks, 1940).

No single congenital defect can explain the development of aneurysms from the bases of all the aortic sinuses. Aneurysms of the sinuses of Valsalva usually arise from the inferior aspect of the sinuses, well below the orifices of the coronary arteries where the base of the aorta is attached to the annulus fibrosus. The annulus fibrosus marks the fusion of the aorta with the atrioventricular cushions, the interventricular septum, and proximal bulbar septum. The annulus fibrosus receives the muscle fibres of the left ventricle and the media of the aorta and presents three deep semicircular notches which correspond to the attachment of the aortic cusps. The middle coat of the artery is thin at this point and the vessel is dilated to form the aortic sinuses. Venning (1951) considers failure of development of the medial coat at this level to be the basic cause of the congenital aneurysms. However, the thinness of the aortic media makes it unlikely that this alone can account for the aneurysms. 
The position of the aneurysms suggests a defect at the aortic attachment of the annulus fibrosus or in the annulus itself. This could be explained by defective development of the endocardial cushions which form the pulmonary and aortic valves. A criticism of this hypothesis is that congenital aneurysms of the pulmonary sinus have not been described, but this may be due to the lower blood pressure in the pulmonary circuit. In favour of this hypothesis is the abnormality of the aortic cusps that not infrequently accompanies congenital sinus aneurysms due to failure of bisection of one lateral bulbar endocardial cushion (Hirschboeck, 1942; Herson and Symons, 1946; Case 2 of this series).

Apart from abnormalities of the aortic cusps, other congenital malformations occur and the most common according to Brown (1950) is a defect in the bulbar part of the interventricular septum. This is a result of the failure of growth of the right extremity of the fused atrioventricular cushions which joins the caudal border of the proximal bulbar septum to the free sickle-shaped margin of the ventricular septum (Fig. 7). Alternatively a defect of union between the atrio-

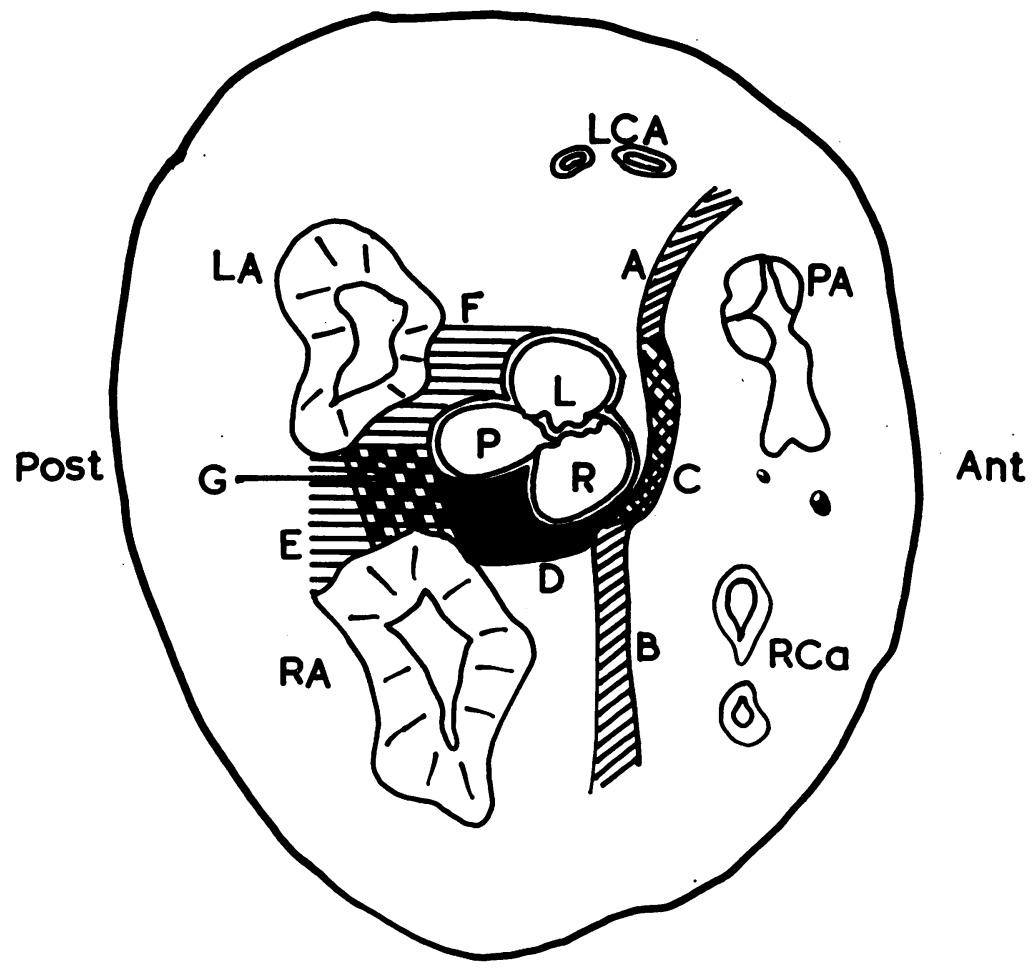

FIG. 7.-Transverse section of the heart at the level of the aortic valve to show the embryological development. (A) Left endocardial cushion. (B) Right endocardial cushion. (C) Distal bulbar septum. (D) Ventricular septum joining the membranous septum which is formed from the fused atrioventricular cushions (G). (E F) Atrioventricular endocardial cushions. (G) Fused atrioventricular cushions. Proliferation of cushion tissue from the right extremity of the fused cushions forms the membranous portion of the interventricular septum. R.A.= Right atrium. L.A. $=$ Left atrium. P.A. $=$ Pulmonary artery. L. $=$ Left (coronary) sinus. $\mathbf{P} .=$ Posterior (non-coronary) sinus. R.=Right (coronary) sinus. L.C.A.=Left coronary artery. R.C.A.=Right coronary artery.

ventricular cushions, interventricular septum, and proximal bulbar septum with the root of the aorta may result in a defect in any of the aortic sinuses.

Previously reported cases show that congenital aneurysms of the right (coronary) sinus are very much commoner than those affecting the other two sinuses. Including our cases, 27 aneurysms 
have been described arising from the right (coronary) sinus, 5 from the posterior, and 4 from the left, all confirmed at necropsy. Rupture of the aneurysms occurred to form cardio-aortic fistulæ in 26 cases.

\section{Discussion}

Abbott (1919) and others have shown that aneurysms that originate in the aortic sinuses and burrow through the ventricular septum produce a distinctive clinical syndrome upon rupture into the right ventricle. When this occurs, the symptoms and signs may be sufficiently characteristic to permit diagnosis during life as happened in Case 1.

Provided there are no accompanying congenital defects, aortic sinus aneurysms are usually symptomless until rupture occurs. Occasionally, however, pressure from the aneurysm on the atrioventricular node and bundle (His) may be sufficient to cause bundle-branch block (Case 2) or even fatal Stokes-Adams attacks (Lee et al., 1956).

The clinical syndrome resulting from rupture of an aneurysm varies according to the site of rupture. If the aneurysm bursts into the right atrium or ventricle, tricuspid regurgitation may follow. Intracardiac fistula between the aorta and the atria or right ventricle are not usually immediately fatal. However, immediate death may follow when left (coronary) sinus or posterior sinus aneurysms rupture into the pericardial cavity.

When a fistula forms between the aorta and the right ventricle or atrium, blood escapes into the latter during diastole producing a diastolic murmur (Case 1) which has a characteristic superficial quality. Occasionally death may occur from associated congenital abnormalities while the aneurysm is still intact, as in Case 2. In the latter, the congenital absence of an aortic cusp allowed free aortic regurgitation and consequently left ventricular hypertrophy. The left axis deviation produced in the electrocardiogram progressed to left bundle-branch block eighteen months before death, as a result of extension of the right (coronary) sinus aneurysm into the interventricular septum.

\section{SUMmaRY}

Two further cases of aneurysms of the aortic sinuses are described. In Case 1, the aneurysm arose from the right (coronary) sinus and ruptured into the right ventricle. There were two aneurysms in Case 2, arising from the left and right (coronary) sinuses, and the latter aneurysm ruptured into the interventricular septum compressing the left branch of the bundle of His. In addition, there was a congenital absence of the right anterior aortic valve cusp.

The embryological development in this form of congenital heart disease is discussed.

We wish to thank Dr. Howard Bell for permission to publish details of Case 1, and Dr. Alan Reitsma for the photographs. Professor T. F. Hewer of the University of Bristol kindly supplied a copy of the necropsy report and the photographs of Case 2. Mr. T. Dee produced Fig. 7.

\section{REFERENCES}

Abbott, M. E. (1919). Contributions to the Medical and Biological Research. Sir William Osler anniversary volume, vol. 2, p. 899 . Hoeber: New York.

(1936). Atlas of Congenital Heart Disease, p. 36. New York.

Brown, J. W. (1950). Congenital Heart Disease, 2nd ed., p. 253. Staples Press, London.

Feldman, L., Friedlander, J., Dillon, R., and Wallyn, R. (1956). Amer. Heart J., 51, 314.

Gray's Anatomy (1942). edit. by T. B. Johnston, and J. Whillis, 28th ed., p. 146. Longmans, Green, London.

Herson, R. N., and Symons, M. (1946). Brit. Heart J., 8, 125.

Higgins, A. R. (1934). U.S. Nav. med. Bull., 32, 47.

Hirschboeck, F. J. (1942). Amer. Heart J., 24, 550.

Jones, M. A., and Langley, F. A. (1949). Brit. Heart J., 11, 325.

Lee, E. B., Krieger, O. T., and Lee, M. K. (1956). Ann. intern. Med., 45, 525.

Micks, R. H. (1940). Brit. Heart J., 2, 63.

Oram, S., and East, T. (1955). Brit. Heart J., 17, 541.

Venning, G. R. (1951). Amer. Heart J., 42, 57.

Walmsley, T. (1929). Quain's Elements of Anatomy. edit. by Sir E. A. Schafer, J. Symington, and T. H. Bryce, 11 th ed., vol. IV, pt. 111, p. 48. Longmans, Green, London. 